\title{
Effect of nanoscale topography and chemical composition of surfaces on their microfrictional behaviour
}

\author{
Y.B. Gerbig ${ }^{\mathrm{a}, \mathrm{c}, *}$, S.I.-U. Ahmed ${ }^{\mathrm{b}}$, D.G. Chetwynd ${ }^{\mathrm{c}}$ and H. Haefke ${ }^{\mathrm{a}}$ \\ ${ }^{a}$ CSEM Swiss Center for Electronics and Microtechnology Inc., Rue Jaquet Droz 1, Neuchâtel CH-2007, Switzerland \\ ${ }^{b}$ Laboratoire des Matériaux et de Technologie des Surfaces, Haute école ARC ingénierie, Hôtel-de-Ville 7, Le Locle CH-2400, Switzerland \\ ${ }^{c}$ School of Engineering, University of Warwick, Coventry CV4 7AL, UK
}

Received 3 July 2005; accepted 22 January 2006; published online 25 April 2006

\begin{abstract}
The influence of nanoscale topography and chemical composition on microfriction has been studied at different humidities. Structured surfaces exhibit lower friction than smooth ones. Among the structured surfaces, the crater-like morphologies show lower friction than pyramid-like morphologies. No significant differences in friction were observed when varying the roughness of the crater-like structures. On pyramid-like morphologies, friction increases with decreasing roughness. Additional hydrophobization of surface nanostructures results in only small reductions in friction.
\end{abstract}

KEY WORDS: microtribology, nanoscale topography, wettability, hydrophilic and hydrophobic surfaces

\section{Introduction}

The functionality and efficiency of many microsystems depend strongly on their surface wettability [1,2]. For example, poor wettability with water (or hydrophobicity) results in a decrease of pull-off forces in head/ disk systems or a reduction of flow resistance in microfluidics. It is known that the wettability of surfaces is affected by their chemical composition and topography [3-5]. Yet, the combined influence of both factors has not been studied systematically. Two main approaches have been applied in order to topographical modification of materials. The first approach consists of structuring or patterning hydrophobic/hydrophilic film surfaces during or after deposition onto a smooth substrate. This is achieved by various methods such as embedding minute particles [6], post treatment with ion or electron beam [7] and plasma etching [8]. In the other approach, a hydrophobic/hydrophilic material is deposited on structured or patterned substrates produced by methods like embossing, laser ablation [9], photolithography [10] or deposition of a rough interlayer by thin film technology $[11,12]$. The rough-interlayer method is a good candidate for microsystems and microfluidic devices because it can be applied to three-dimensional surfaces [11].

In this paper, the rough-interlayer approach has been applied to a study of the influence of nanoscale topographical features on wettability (with water) and microtribological behaviour. The goal of the investigation is to gain knowledge about the influence of the

\footnotetext{
*To whom correspondence should be addressed. E-mail: y.b.gerbig@warwick.ac.uk
}

structure shape as well as the dimension of topographical features on the functionality of hydrophilic and hydrophobic surfaces.

\section{Experimental work}

\subsection{Sample preparation}

Six chromium nitride $(\mathrm{Cr}-\mathrm{N})$ coatings with different structures were deposited on $\mathrm{Si}(100)$ wafers. Samples labelled P1-P3 exhibit a pyramid-like topography, while the samples labelled $\mathrm{C} 1-\mathrm{C} 3$ are characterized by a crater-like topography. The interpretation of these descriptive terms can be seen in figure 1: pyramid-like surfaces consists of an irregular array of upwardly tapered features with simple faceted flanks, while craterlike topographies are random structures topographically similar to those obtained by bombarding a surface from above with particles or brief energy bursts. In both cases, the dimensions of the surface features were varied (see figure 1 and table 1).

All samples were prepared by unbalanced magnetron (UBM) sputtering in a physical vapour deposition process (PVD). The different structures were obtained by adjusting the parameters of the PVD process in a controlled manner (table 2). A reference sample, consisting of a highly polished $\mathrm{Si}(100)$ surface, was used to compare the performance of the structured samples and is hereafter referred to as the reference.

To alter the chemical behaviour from hydrophilic to hydrophobic, the reference and the structured $\mathrm{Cr}-\mathrm{N}$ thin films were coated with either silicon oxide to make them 
hydrophilic or with fluorocarbon to render them hydrophobic. The thickness of the silicon oxide and fluorocarbon layer was set to $10 \mathrm{~nm}$ to avoid smoothing of the structured surfaces. The silicon oxide layer was deposited by RF sputtering from a silicon oxide target with a power of $150 \mathrm{~W}$ under a pressure of $0.4 \mathrm{~Pa}$ and zero bias voltage. For depositing the fluorocarbon layer, the samples were cleaned in an oxygen plasma (ignited at $0.4 \mathrm{~Pa}$ ). Afterwards the fluorocarbon layer was obtained by using hexafluoropropene gas at $0.3 \mathrm{~Pa}$ with a bias voltage between 1.2 and $1.4 \mathrm{kV}$ and currents between 13 and $15 \mathrm{~mA}$. The process is described in detail elsewhere [13]. AFM and SEM observation of the surfaces coated with silicon oxide or fluorocarbon indicate that these layers cover the surface of the $\mathrm{Cr}-\mathrm{N}$ films homogenously.
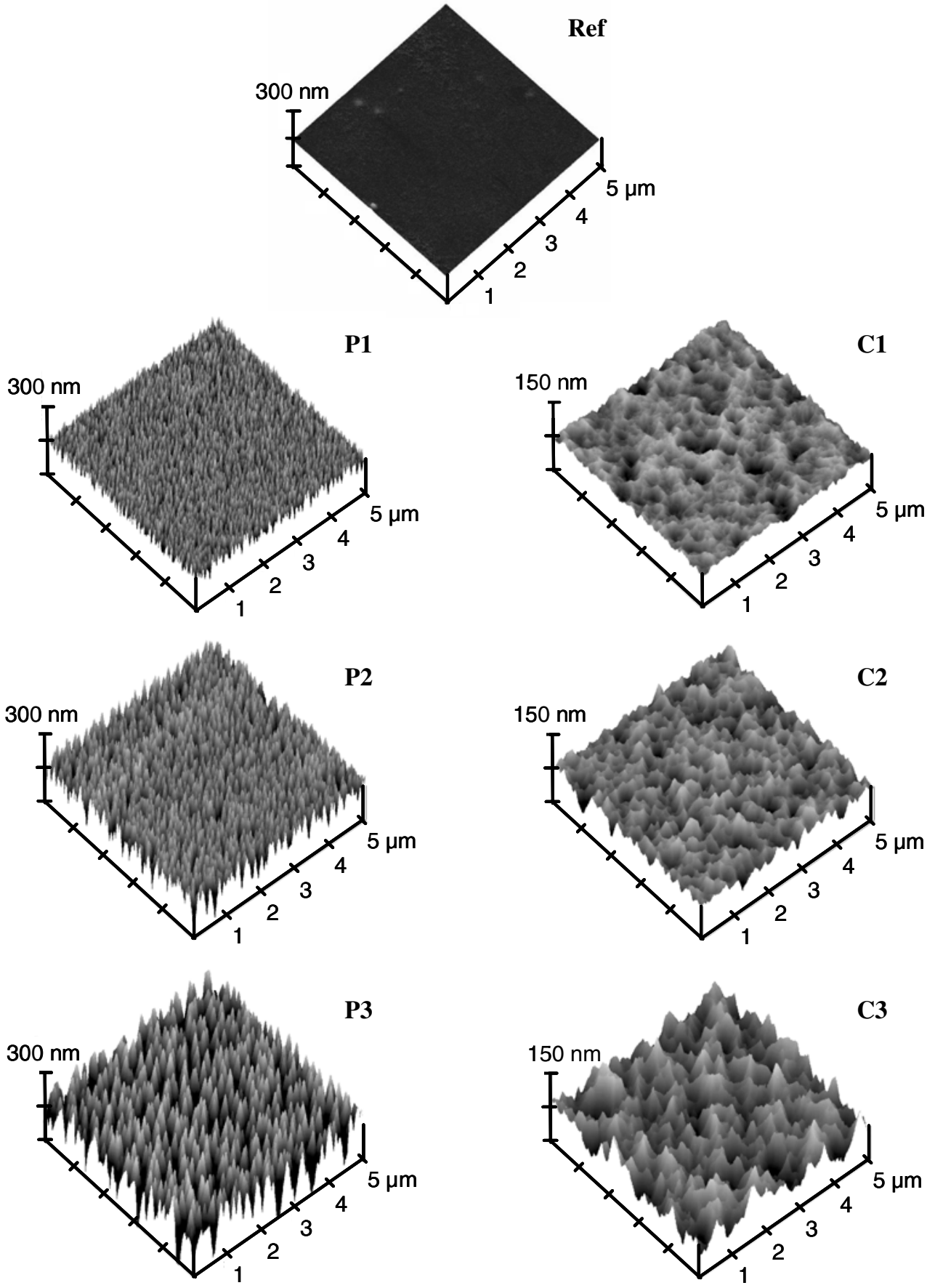

Figure 1. AFM images of the reference (Ref), pyramid-like (P1-P3) and crater-like (C1-C3) structured Cr-N surfaces after coating with a thin silicon-oxide layer. Similar morphologies were obtained with surfaces coated with a fluorocarbon layer. 
Table 1.

Root mean square roughness $\left(S_{\mathrm{q}}\right)$, number, slope and curvature of the asperities on the tested reference (Ref.), the pyramid-like structures (P1-P3) and the crater-like structures (C1-C3) after coating with silicon oxide or fluorocarbon layer, respectively, measured by AFM (scan size $5 \times 5 \mu \mathrm{m}^{2}$ ).

\begin{tabular}{|c|c|c|c|c|}
\hline Sample & $S_{\mathrm{q}}(\mathrm{nm})$ & Asperity number (\#) & Asperity slope (nm) & Asperity curvature (nm) \\
\hline Ref. & $2.1 \pm 0.2$ & $229 \pm 30$ & $0.200 \pm 0.02$ & $32 \pm 2$ \\
\hline P1 & $17.9 \pm 0.7$ & $599 \pm 98$ & $0.870 \pm 0.008$ & $6 \pm 0.4$ \\
\hline P2 & $34.4 \pm 0.5$ & $357 \pm 45$ & $0.872 \pm 0.018$ & $6 \pm 0.5$ \\
\hline P3 & $59.6 \pm 0.6$ & $98 \pm 20$ & $0.906 \pm 0.022$ & $6 \pm 0.2$ \\
\hline $\mathrm{C} 1$ & $9.6 \pm 0.2$ & $23 \pm 6$ & $0.109 \pm 0.008$ & $113 \pm 10$ \\
\hline $\mathrm{C} 2$ & $15.6 \pm 0.9$ & $20 \pm 6$ & $0.125 \pm 0.012$ & $154 \pm 8$ \\
\hline $\mathrm{C} 3$ & $30.3 \pm 1.0$ & $23 \pm 6$ & $0.139 \pm 0.008$ & $143 \pm 7$ \\
\hline
\end{tabular}

\subsection{Characterization of topography}

The topography of the reference samples and the differently structured surfaces were analysed by atomic force microscopy (AFM) after depositing the silicon oxide or the fluorocarbon layers. To avoid a damage of the nanostructures, all AFM images was performed in tapping mode using a conical silicon high resonance frequency probe tip (force constant: $5.5 \mathrm{~N} / \mathrm{m}$, tip curvature: $10 \mathrm{~nm}$, resonant frequency: $150 \pm 5 \mathrm{kHz}$ ). The surface roughness was analysed by recording AFM images of 10 areas (scan size $5 \times 5 \mu \mathrm{m}^{2}$ ) measured at different locations on the samples surface. In this study, auto-levelling using a least squares plane was applied before calculating the surface parameters from AFM scans (by using the software Nanoscope III version $5.12 \mathrm{r} 3$ by Digital Instruments). In all scans there were 256 sampling points in both $x$ and $y$ directions. The surface structure of the samples showed that the roughness values of the surfaces coated with silicon oxide are comparable to the values obtained after fluorocarbon deposition. Therefore, the average roughness values, listed in table 1 , were calculated from measurements conducted on hydrophilic as well as hydrophobic samples. Beside the commonly used $S_{\mathrm{q}}$ and $S_{\mathrm{z}}$ values, the asperity (peak) number was also calculated. The asperity number counts all asperities in the scanned area, which are distributed within $5 \mathrm{~nm}$ from the highest point in the scanned area.

Table 2 .

PVD parameters used in reactive unbalanced magnetron (UBM) sputtering process for depositing the different surface structures on $\operatorname{Si}(100)$.

\begin{tabular}{lccccc}
\hline Structure & $\begin{array}{c}\text { Temperature } \\
\left({ }^{\circ} \mathrm{C}\right)\end{array}$ & $\begin{array}{c}\text { Total } \\
\text { pressure } \\
(\mathrm{Pa})\end{array}$ & $\begin{array}{c}\text { Ar/ } \mathrm{N}_{2} \text { gas } \\
\text { flow ratio }\end{array}$ & $\begin{array}{c}\text { Bias } \\
\text { voltage } \\
(\mathrm{V})\end{array}$ & $\begin{array}{c}\text { Sputter } \\
\text { power } \\
(\mathrm{kW})\end{array}$ \\
\hline P1 & 150 & 1.0 & 1.5 & 0 & 2 \\
P2 & 150 & 0.4 & 1.5 & 0 & 2 \\
P3 & 200 & 1.0 & 1.3 & -5 & 6 \\
C1 & 450 & 1.0 & 0.7 & -225 & 2 \\
C2 & 250 & 1.0 & 1.5 & -225 & 2 \\
C3 & 350 & 0.4 & 1.0 & -225 & 4 \\
\hline
\end{tabular}

For the pyramid-like samples, increase of the surface roughness is related to larger but fewer pyramidal surface features within the same scan area (figure 1). For the crater-like samples, the increase in the surface roughness is caused by deeper craters whereas the number of surface features remains relatively constant (figure 1).

\subsection{Wettability analysis}

The advancing contact angle $\left(C_{\mathrm{A}}\right)$ and receding contact angle $\left(C_{\mathrm{R}}\right)$ were determined by the sessile drop method at room temperature using the Krüss Drop Shape Analyser System DSA 10. The $C_{\mathrm{A}}$ value was determined while the droplet $\left(4.2 \mathrm{~mm}^{3} \pm 5 \%\right)$ was distended by pumping de-ionized water from a micro-syringe onto the surface $(1 \mu \mathrm{L} / \mathrm{s} \pm 5 \%)$ whereas $C_{\mathrm{R}}$ was measured while the drop volume was reduced. The average values for $C_{\mathrm{A}}$ and $C_{\mathrm{R}}$ were calculated from measurements carried out on five different areas on the sample surface.

\subsection{Microtribological tests}

Comparative microfriction studies were performed by using a precision microtribometer. This microtribometer (figure 2) consists of three basic units: precision motion mechanisms, force transducer and fibre-optic length detection system [14]. The precision motion mechanisms consist of various drives for sample positioning, providing reciprocating motion and for normal force adjustment. The sample positioning drives are stepper motors, while the reciprocating unit consists of a piezo element coupled to a linear guide. Coarse normal force adjustment is achieved by using a stepper motor, while fine adjustment is accomplished with a piezo element. The force transducer is a double leaf spring made from photo-structured glass. By knowing the lateral and the normal force constants of the spring, measured lateral and normal deflections can be transformed to their respective force values. The deflections of the spring, the back and forth motion of the reciprocating unit as well 
as the vertical motion of the normal force adjustment unit are all measured using fibre-optic sensors based on the principle of reflection intensity variation. More details about design and principle of measurement of this test device are described elsewhere [15].

In this work, microtribological tests consisted of measuring the friction force as function of the relative humidity at a normal load of $0.2 \mathrm{mN}$, sliding speed of $50 \mu \mathrm{m} / \mathrm{s}$ and stroke of $100 \mu \mathrm{m}$.

Prior to the tribological measurements, the mechanical stability of the surface structures and the wear resistance of the covering layer were investigated in wear mapping tests. As SEM analysis of the tested surfaces have shown, the covering layer remains on the asperity peaks for loads below $1 \mathrm{mN}$, and the onset of observable wear (e.g. plastic deformation) of the structured surfaces occurs just above $10 \mathrm{mN}$. Based on these results it was concluded that the surfaces are stable under the remainder of test conditions applied in this study. This conclusion was confirmed by subsequent tribological measurements in that the friction force is constant in each test over the test duration of 10 cycles. As an example, a friction curve recorded for the hydrophilic structure $\mathrm{P} 1$ at $10 \% \mathrm{RH}$ is shown in figure 3 . The relative humidity was increased going from $10,30,50,70,90 \pm 3 \%$ R.H at $20 \pm 2{ }^{\circ} \mathrm{C}$ in the tests. Before starting tribological measurements, the humidity was kept at the desired value for four hours.

The counter bodies in the tribological tests were $2 \mathrm{~mm}$ diameter steel AISI $440 \mathrm{C}$ balls coated with titanium carbide $(\mathrm{TiC})$ and were polished after deposition.

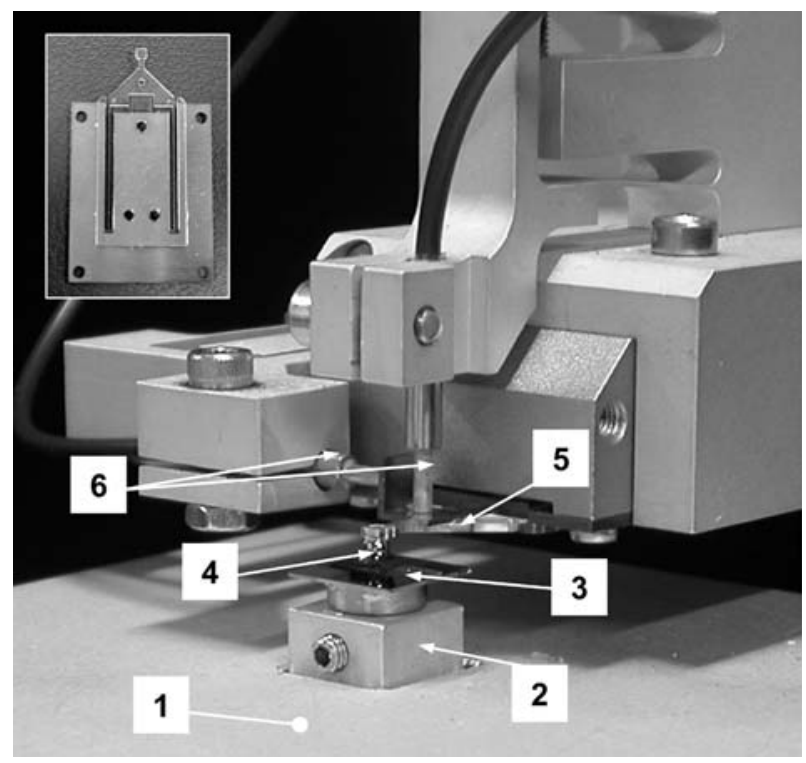

Figure 2. Image of the microtribometer. The main components are marked: (1) $x-y$ micropositioning stage powered by stepper motors (2) reciprocating unit, (3) sample, (4) counter body, (5) force transducer, (6) fibre-optic sensors to detect normal and lateral deflections of the force transducer. The inset shows a glass spring force transducer mounted on a steel support.
The TiC coating on the balls had a $S_{\mathrm{q}}$ roughness of $2.8 \pm 1 \mathrm{~nm}$ and a surface hardness of $35 \pm 2 \mathrm{GPa}$. Contact angles of $58 \pm 2^{\circ}$ were determined for the $\mathrm{TiC}$ coating; the coatings exhibit hydrophilic behaviour. The wettability measurements were carried out on $\mathrm{TiC}$ coated discs instead of balls. Discs and balls were coated during the same deposition process.

All microtribological tests followed the same procedure. Prior to each experiment, the balls were cleaned in an ultrasonic bath first in acetone, then in isopropanol and finally in ethanol, for $10 \mathrm{~min}$ each. Since the investigated surfaces were stored in sealed boxes immediately after being coated, the samples were just swiped with a lint-free tissue soaked in ethanol before performing the experiments. The counter body was brought in contact with the surface and the normal load was then applied. The reciprocating motion was initiated for 10 cycles and the friction force was continually recorded during motion. After completion, the reciprocating motion was terminated and the counter body removed from the surface. All experiments were repeated at least three times at new locations on the surface to ensure reproducibility of the results.

\section{Results and discussion}

\subsection{Influence of structure on wettability}

The average values for $C_{\mathrm{A}}$ and $C_{\mathrm{R}}$ measured on the different surfaces after coating with silicon oxide or fluorocarbon are given in table 3 .

The different surface chemistry caused by the deposition of the silicon oxide or fluorocarbon film results, as expected, in different water wettability: hydrophilic or hydrophobic, respectively.

When coated with silicon oxide, the reference sample and the three samples with a crater-like morphology exhibit similar $C_{\mathrm{A}}$ and $C_{\mathrm{R}}$ values that lie between $40^{\circ}$ and $50^{\circ}$, whereas the pyramid-like structures show contact angles of only $9-10^{\circ}$. This implies that the pyramid-like structures are more hydrophilic compared to the reference and crater-like structures. Comparing the

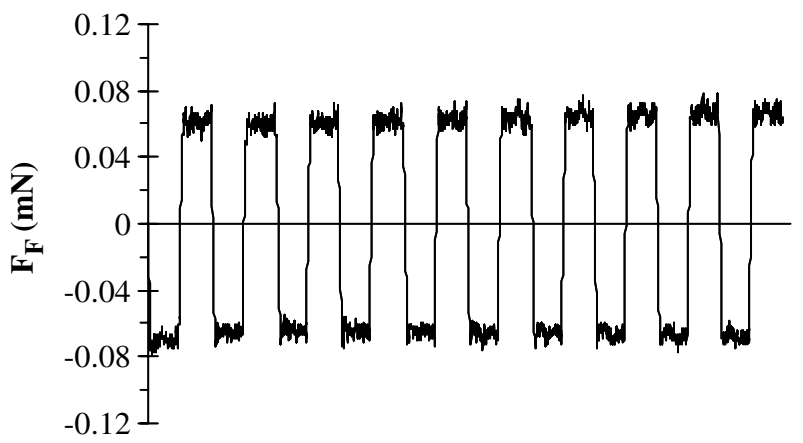

Figure 3. Friction force signal recorded during 10 cycles on the hydrophilic sample of structure $\mathrm{P} 1$ at $10 \% \mathrm{RH}$. 
Table 3 .

Advancing $\left(C_{\mathrm{A}}\right)$ and receding $\left(C_{\mathrm{R}}\right)$ contact angles determined on the smooth reference (Ref.), the pyramid-like structures (P1-P3) and the craterlike structures $(\mathrm{C} 1-\mathrm{C} 3)$ coated with silicon oxide or fluorocarbon films.

\begin{tabular}{|c|c|c|c|c|c|}
\hline \multirow[t]{2}{*}{ Sample } & \multicolumn{2}{|c|}{+ silicon oxide film } & \multicolumn{3}{|c|}{+ fluorocarbon film } \\
\hline & $C_{\mathrm{A}}($ deg. $)$ & $C_{\mathrm{R}}$ (deg.) & $C_{\mathrm{A}}(\mathrm{deg})$. & $C_{\mathrm{R}}$ (deg.) & $C_{\mathrm{A}}-C_{\mathrm{R}}$ (deg.) \\
\hline Ref. & $51 \pm 2$ & $40 \pm 1$ & $100 \pm 2$ & $60 \pm 2$ & $40 \pm 4$ \\
\hline P1 & $10 \pm 1$ & $10 \pm 1$ & $142 \pm 2$ & $30 \pm 2$ & $112 \pm 4$ \\
\hline $\mathrm{P} 2$ & $9 \pm 1$ & $10 \pm 2$ & $136 \pm 2$ & $34 \pm 2$ & $102 \pm 4$ \\
\hline P3 & $10 \pm 1$ & $10 \pm 1$ & $138 \pm 2$ & $30 \pm 2$ & $108 \pm 4$ \\
\hline $\mathrm{C} 1$ & $50 \pm 2$ & $45 \pm 2$ & $112 \pm 2$ & $68 \pm 2$ & $44 \pm 4$ \\
\hline $\mathrm{C} 2$ & $49 \pm 1$ & $42 \pm 2$ & $108 \pm 2$ & $66 \pm 2$ & $42 \pm 4$ \\
\hline $\mathrm{C} 3$ & $50 \pm 3$ & $45 \pm 2$ & $108 \pm 2$ & $70 \pm 2$ & $38 \pm 4$ \\
\hline
\end{tabular}

For easier comparison of the different hydrophobic surfaces, the contact angle hysteresis $(\mathrm{CA}-\mathrm{CR})$ is listed additionally.

samples with the same type of structure but differently sized surface features against each other revealed that the wettability does not appear to be influenced by the size of the surface features.

Usually, the contact angle of freshly prepared silicon oxide surfaces is expected to be below $10^{\circ}$. Compared to this value, the contact angle measured on silicon oxide in this study is quite high. However, similarly high contact angles on silicon oxide surfaces were also reported in literature [16]. The variation in the wettability is commonly explained by difference in the preparation method and the altering of the surfaces properties by absorption of organic materials $[16,17]$. In this context, it is interesting to note that significantly smaller contact angles were measured on the silicon oxide covered pyramid structures than for smooth and crater-like structured samples with identical surface chemistry. The enhanced wetting of spiky surfaces was also observed by Bico et al. [18] and was attributed to the enhanced sucking of liquid into the surface cavities on this type of surface structure. It is believed that a similar effect causes the observed differences in the wettability of different surfaces in this study.

With the fluorocarbon film, $C_{\mathrm{A}}$ values between $100^{\circ}$ and $112^{\circ}$ and $C_{\mathrm{R}}$ values between $60^{\circ}$ and $70^{\circ}$ were recorded on the smooth reference and the crater-like structures $(\mathrm{C} 1-\mathrm{C} 3)$. The samples $\mathrm{P} 1-\mathrm{P} 3$ had $C_{\mathrm{A}}$ values of $136-142^{\circ}$ and $C_{\mathrm{R}}$ values in the range of $30-34^{\circ}$. No effect of the size of the surface features on wettability could be detected on these hydrophobic samples. A comparison of the $C_{\mathrm{A}}$ values measured on the different surface morphologies revealed that tapered surface features are required to gain an increase in the water contact angle. This is in good agreement with the work of other groups [19-21] who observed higher contact angles for uniformly distributed, sharp protuberances. It has been suggested that the air trapped between the protuberances supports the bottom of the water droplet leading to a transition from nanocomposite surface (completely liquid-solid interface $=$ Wenzel regime) to a composite surface (including trapped air $=$ Cassie regime) $[20,21]$.

\subsection{Influence of structure on frictional behaviour}

\subsubsection{Friction on hydrophilic surfaces}

Figure 4 shows the friction force $\left(F_{\mathrm{F}}\right)$ measured in different relative humidities for the reference surface, the pyramid-like structured samples $\mathrm{P} 1-\mathrm{P} 3$ and the craterlike structured samples $\mathrm{C} 1-\mathrm{C} 3$.

At all humidities tested, the friction measured on the smooth reference surface is considerably higher than on any of the structured surfaces. On the reference surface, the friction increases with the relative humidity until reaching $70 \% \mathrm{RH}$. On increasing the humidity to $90 \%$ $\mathrm{RH}$, the friction remains at a similar level as obtained for $70 \% \mathrm{RH}$.

With increasing size of the pyramidal surface features, or increasing surface roughness, friction decreases under the given test conditions of this work (figure 4). This is due to a reduced number of contacting points and, thus, decreased area of contact between sample and counterbody. Furthermore, each pyramid-like structure appears to be sensitive to humidity changes. As relative humidity rises, the friction at first increases and reaches a maximum value at $50 \% \mathrm{RH}$. However, this increase is far less than that recorded on the smooth surface. A further increase of the humidity to 70 and $90 \% \mathrm{RH}$ leads to a gradual decrease of the friction although the friction forces measured at $90 \% \mathrm{RH}$ remain higher than the values recorded at $10 \% \mathrm{RH}$. A similar effect has been reported by Binggeli and Mate [22] for sliding a single asperity against a smooth surface. In this case the decrease of friction with increasing humidity was attributed to reduced shearing force due to pushing of unbound water molecules into the microasperity contact junction.

In comparison to reference and pyramid-like morphologies, the friction on the crater-like structured samples does not change to any large extent with varying humidity. Only a very slight rise of the friction force following the pattern of behaviour observed for the pyramid-like structures becomes noticeable on the rougher samples. For the samples with crater-like morphology, the friction tends also consistently to be 
higher with increasing roughness although the variation is small and perhaps insignificant (figure 4). Unlike the pyramid structures, the number of asperities does not change with modifying the surface roughness of the crater morphology (see table 1). That means that the area of contact remains nearly constant for the different crater-like structures.

Generally, lower friction was recorded on the craterlike morphologies than on the pyramid-like structures. This could be due to the different asperity slope and curvature.

\subsubsection{Friction on hydrophobic surfaces}

The friction force measured in different relative humidities is shown in comparison to the reference surface for the pyramid-like structured samples P1-P3 and for the crater-like structured samples $\mathrm{C} 1-\mathrm{C} 3$ in figure 5 .

In all cases, the friction force measured on the smooth reference surfaces is higher than on any of the structured surfaces. The friction force measured on the pyramid-like structures P1-P3 decreases with increasing roughness, the same pattern as seen with hydrophilic pyramid-like structures. It is assumed that, as described for the hydrophilic samples, the decrease in the area of contact might cause a lower friction on rougher surfaces. Again, the crater-like structures C1C3 showed equally the lowest forces.

There was no significant variation of friction force with humidity in any of the tests. The same result was also reported by Scherge and Gorb [23]. Compared to the hydrophilic sample with identical surface structure, the friction force was rather lower (typically by about $30 \%$ ) on the hydrophobic sample.

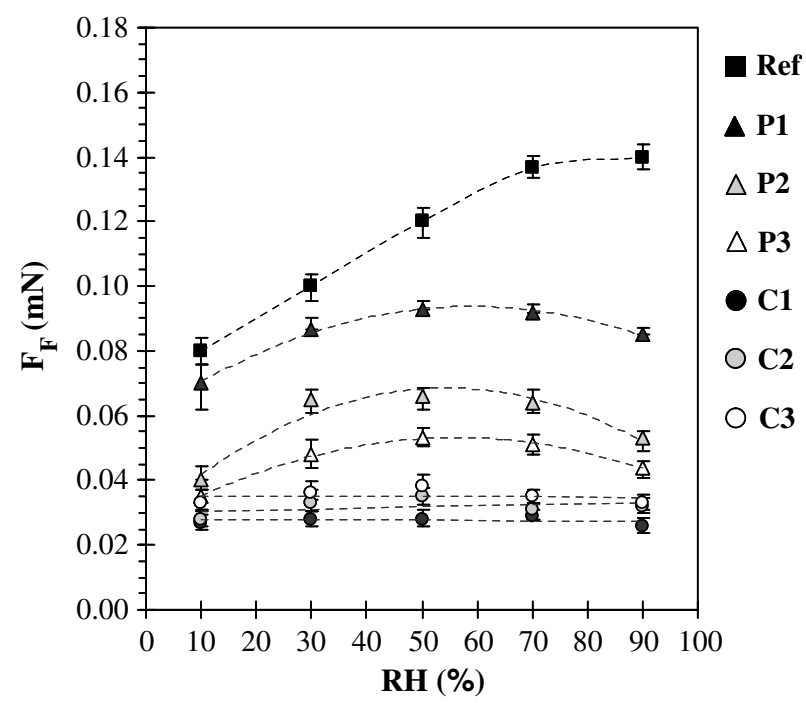

Figure 4. Friction force $\left(F_{\mathrm{F}}\right)$ as function of the relative humidity $(\mathrm{RH})$ measured on hydrophilic surfaces with a pyramid-like (P1-P3) and a crater-like $(\mathrm{C} 1-\mathrm{C} 3)$ surface topography and compared to a smooth reference surface (Ref). The vertical bars represent the variation between the minimum and maximum value in those tests.

\subsubsection{Comparison between friction on hydrophilic and hydrophobic surfaces}

The underlying mechanism of friction reduction of structured surfaces due to varying contact areas may be interlocking effects [24] or capillarity [25] or even solidsolid adhesion (bonding) between the two surfaces [26], or combinations thereof. To estimate the relevance of capillarity for the investigated system, the maximum capillary force $F_{\mathrm{C}}$ (which might occur under the conditions of ideally smooth mating surfaces) was calculated accordingly equation 1 and compared to the applied normal load:

$$
F_{\mathrm{C}}=2 \pi R \gamma\left(\cos \theta_{1}+\cos \theta_{2}\right)
$$

$R$ is the radius of the counter body $(R=1 \mathrm{~mm}), \gamma$ is the surface tension of water $\left(\gamma=72.8 \mathrm{~mJ} / \mathrm{m}^{2}\right), \theta_{1}$ is the contact angle of water on the counter body $\left(\theta_{1}=58.2^{\circ}\right.$ for $\mathrm{TiC}$ ) and $\theta_{2}$ is the contact angle of water on the sample $\left(\theta_{2}=51^{\circ}\right.$ for silicon oxide on reference surface).

It was found that the capillary and normal force is in the same range. Therefore, capillarity has to be considered as a possible contribution to the friction force in the system even though the actual value might be presumably smaller than the calculated one due to roughness effects. However, in this study the capillary force could not be calculated for the rough surfaces, since the exact geometry of the contact between sample and counter body is not known.

The surface roughness of the reference sample is lower than on the structured samples, so the effect of interlocking should be much higher on the rougher structured samples than on the smooth reference. In the case of experiments performed on hydrophobic surfaces at low relative humidity, the interlocking should then be

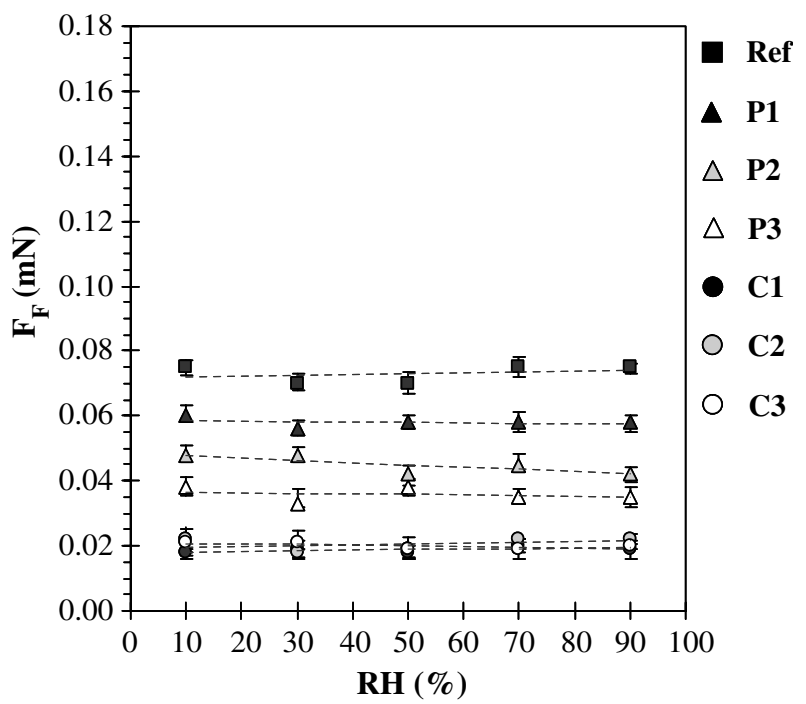

Figure 5. Friction force $\left(F_{\mathrm{F}}\right)$ as function of the relative humidity $(\mathrm{RH})$ measured on hydrophobic surfaces with pyramid-like (P1-P3) and crater-like (C1-C3) surface features compared to a smooth reference surface (Ref). The vertical bars represent the variation between the minimum and maximum value in those tests. 
the major effect on the structured surfaces and thus, the friction is expected to be higher on this surface than on the reference sample. Such behaviour was not observed (see figure 5), this suggests that interlocking effects do not play a dominant role in this study.

Solid-solid adhesion cannot be neglected, since for the hydrophobic samples the contact mechanisms seems to influence the friction force and presumably cause the found variation in friction between the different pyramid structured samples. However, the variation in material and thus, the material-related difference in solid-solid adhesion, appear to be of minor importance. Otherwise, a difference in the friction force values should be measurable between hydrophilic and hydrophobic samples at low humidity, but the friction force values are similar at $10 \% \mathrm{RH}$ for most of the investigated structures. Therefore, it seems that under the given test conditions, for smooth surfaces the capillarity occurring between asperities on samples and counter body strongly contributes to the friction in the system. The hydrophilic surface can adsorb more water in a more humid environment, leading to higher friction forces. However, at a certain point (in this case above $70 \% \mathrm{RH}$ ) the thickness of the adsorbed water film keeps constant and the friction force saturates [23].

The question is whether capillarity is also the main mechanism in structured surfaces. Generally, a lower friction was recorded on the crater-like structure than the pyramid-like structures. This might be explained, beside differences in the contact area, with the higher probability of liquid bridging on the pyramid-like morphology than on the crater-like structure due to higher numbers of surface asperities on the former structure type and shape of the apex of the typical asperity. A reduction of the number of asperities contacting the counterbody causes a decreased effect of the capillary bridging and leads, therefore, to a lower friction force [23].

Capillary effects might also be the reason for the measured difference in friction between hydrophilic and hydrophobic samples with the same structure (compare figures 4 and 5) because the difference in material $\left(\mathrm{SiO}_{2}\right.$ or fluorocarbon) does not seem to affect the friction force. On hydrophobic samples, the capillary force is expected to be significantly lower than on the hydrophilic surfaces. The results of the study indicate that the capillary appears to be even negligible for hydrophobic samples because a humidity-dependence of the friction force was not observed (figure 5). Therefore, it is assumed that the difference in the friction force between hydrophobic and hydrophilic surface is related to the missing (not detectable) contribution of a capillary force.

Furthermore, capillary effects may explain why the difference between hydrophilic and hydrophobic samples is less pronounced with increasing surface roughness of the pyramid structures (figure 6). Since the P1 structure exhibits a higher number of asperities than the other structures, and more locations for capillary bridging are thus available, the capillary effects are detectable already at lower humidities on this surface structure. On samples with fewer asperities (P2 and P3), a higher amount of water (higher humidity) is required to build the capillary bridges in sufficient number to measurably influence the friction in the tribosystem.

\subsubsection{Correlation between surface wettability and frictional behaviour}

As expected, the study showed that wettability has a significant effect on the frictional behaviour of the smooth reference surface: the hydrophobic samples exhibit lower friction force values than the hydrophilic ones (see figures 4 and 5). However, conventional contact angle measurements appear to be less suitable to correlate wettability and frictional behaviour of differently structured surfaces with identical surface chemistry. Regarding the friction measurements on the different hydrophilic samples, the reference surface shows higher values for the contact angles (is less hydrophilic) than the pyramid-like structures even though lower friction occurred on the latter sample. Moreover, the crater-like specimens showed similar contact angle to the reference surface but also showed lower friction forces than those of all the pyramid-like structures. A comparison between hydrophobic samples with different structures is complicated by the fact that the pyramid-like structures exhibit higher $\mathrm{C}_{\mathrm{A}}$ values, but at the same time lower $C_{\mathrm{R}}$ values than the reference and the crater-like structures. In this case, it might be helpful to consider only the hysteresis of the contact angles: a value between $38^{\circ}$ and $44^{\circ}$ was found for the reference and the crater-like structures, and values of $108-112^{\circ}$ for the pyramid-like structures were obtained (see table 3 ). Although a larger hysteresis corresponds to lower waterrepellency of the surface $[10,19]$, the pyramid-like structures maintain lower friction than the smooth surface (figure 5).

\section{Conclusions}

This study shows the importance of performing investigations dedicated to friction optimization by nanostructuring. It was found that a significantly lower friction can be obtained by surface nanostructuring due to a change in the contact area. The reduction of friction seems to depend strongly on the type of nanostructure. The pyramid-like structured surfaces had higher friction than crater-like structures. The effect of the relative humidity is not as pronounced on nanostructures as it is on the smooth surface. Among the structured surfaces the pyramid-like structures show a stronger dependence on the relative humidity than the crater-like ones.

In contrast to flat surfaces, additional hydrophobization of nanostructures only slightly reduces friction, 
hydrophilic $\square$ hydrophobic
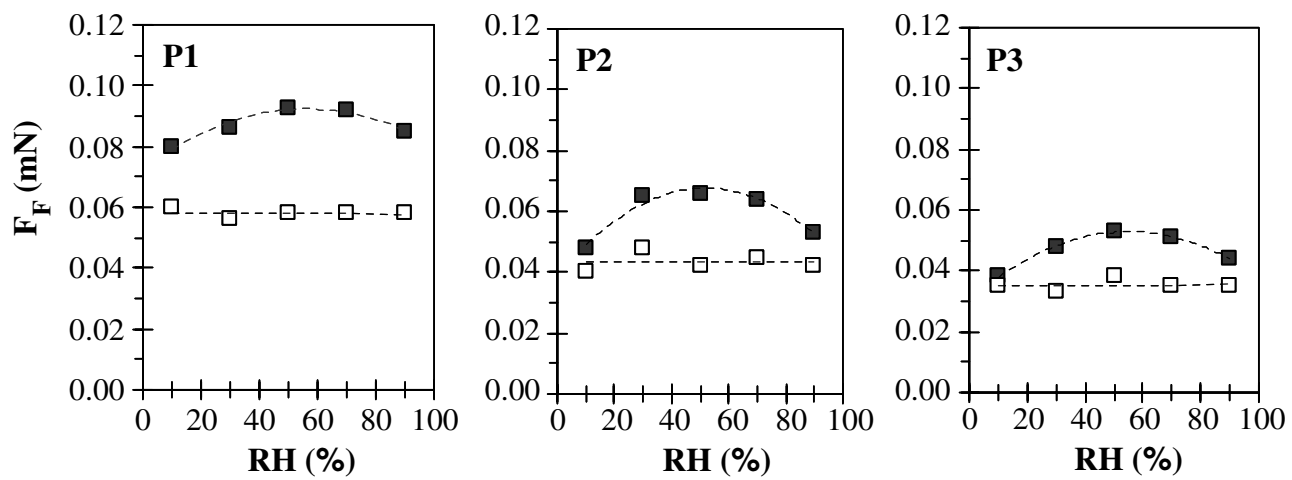

Figure 6. Friction force $\left(F_{\mathrm{F}}\right)$ as function of relative humidity $(\mathrm{RH})$ measured on hydrophilic and hydrophobic samples of the same pyramid-like structure P1, P2 and P3.

especially for crater-likes structures. A clear correlation between wettability and the friction force measurements on differently structured surfaces with identical surface chemistry, which one might expect to see, could not be found in this study. That might be due, in part, to the fact that conventional contact angle measurements are not sufficiently sensitive to topographical changes in the nanoscale range.

Capillarity appears to play a dominant role in defining the friction behaviour of the smooth as well as the structured surfaces. For the structured surfaces, the activation of capillary effects depends on the type, shape and number of asperities present on the surface.

\section{Acknowledgment}

The authors thank V. Spassov (CSEM) and Y. Keles (CSEM) for preparing the silicon oxide films and fluorocarbon films, respectively.

\section{References}

[1] Y. Ando and J. Ino, Wear 216 (1998) 115.

[2] S. Usui, N. Umehara and K. Kato, Proceedings of International Tribology Conference, Nagasaki, Vol. 1 (2000) p. 739.

[3] R.N. Wenzel, Ind. Eng. Chem. 28 (1936) 988.

[4] A.B.D. Cassie and S. Baxter, Trans. Faraday Soc. 40 (1944) 546.

[5] T. Onda, S. Shibuichi, N. Satoh and K. Tsujii, Langmuir 12 (1996) 2125.

[6] H. Saito, K. Takai and G Yamauchi, Surf. Coat. Inter. 4 (1997) 168.
[7] W. Chen, A.Y. Fadeev, M.C. Hsieh, D. Öner, J. Youngblood and T.J. McCarthy, Langmuir 15 (1999) 3395.

[8] K. Teshima, H. Sugimura, Y. Inoue, O. Takai and A. Takano, Appl. Surf. Sci. 244 (2005) 619.

[9] M. Thieme, R. Frenzel, S. Schmidt, F. Simon, A. Henning, H. Worch, K. Lunkwitz and D. Scharnweber, Adv. Eng. Mater. 9 (2001) 691.

[10] D. Öner and T.J. McCarthy, Langmuir 16 (2000) 7777.

[11] T. Uelzen and J. Müller, Thin Solid Films 434 (2003) 311.

[12] Y.B. Gerbig, A.R. Phani and H. Haefke, Appl. Surf. Sci. 242 (2005) 251.

[13] H.F. Knapp and A. Stemmer, Surf. Interface Anal. 27 (1999) 324.

[14] M. Scherge, I. Ahmed, O. Mollenhauer and F. Spiller, Technisches Messen 67 (2000) 324.

[15] O. Mollenhauer, S.I.-U. Ahmed, F. Spiller and H. Haefke, Symposium TRIMIS 2003: Microtribology - Tribology in Microsystems, 1-3 June 2003, Neuchâtel (2003).

[16] G. Bregliozzi, Microtribology of Functional Surfaces for Microengineering Applications, Ph.D. dissertation, University of Perugia, Italy (2005).

[17] S. Takeda and M. Fukawa, Thin Solid Films 444 (2003) 153.

[18] J. Bico, U. Thiele and D. Quéré, Colloid Surf. A 206 (2002) 41.

[19] J.P. Youngblood and T.J. McCarthy, Macromolecules 32 (1999) 6800.

[20] M. Miwa, A. Nakajima, A. Fujishima, K. Hashimoto and T. Watanabe, Langmuir 16 (2000) 5754.

[21] Y. Inoue, Y. Yoshimura, Y. Ikeda and A. Kohno, Colloid Surf. B 19 (2000) 257.

[22] M. Binggeli and C.M. Mate, Appl. Phys. Lett. 65 (1994) 415.

[23] M. Scherge and S.N. Gorb, Biological Micro- and Nanotribology (Springer, Berlin, 2001).

[24] B. Bhushan, Introduction to Tribology (John Wiley \& Sons, New York, 2002).

[25] J.N. Israelachvili, Surf. Sci. Rep. 14 (1992) 109.

[26] D. Tabor and J Colloid, Interface Sci. 58 (1977) 2. 